\title{
The Influence of Solar Radiation on the Antioxidant Systems in Blood of Dairy Cows and the Processing of the Data Using Wavelets Transforms
}

\author{
Dana Liana PUSTA ${ }^{1}$, Rodica SOBOLU ${ }^{2 *}$, Sanda ANDREI ${ }^{1}$, Camelia RADUCU ${ }^{3}$, Ioana POP ${ }^{2}$, Alexandra \\ TĂBĂRAN ${ }^{1}$, Oana REGET ${ }^{1}$, Mihai BORZAN ${ }^{1}$, Ioan PAȘCA ${ }^{1}$ \\ ${ }^{1}$ Faculty of Veterinary Medicine, USAMV Cluj-Napoca, Romania, ${ }^{2}$ Faculty of Horticulture, USAMV Cluj- \\ Napoca, Romania, ${ }^{3}$ Faculty of Animal Husbandry, USAMV Cluj-Napoca, Romania \\ *corresponding author: rodica.sobolu@usamvcluj.ro
}

\begin{abstract}
The purpose of this paper was to observe if in cattle, exposed to the solar radiation, could be noticed a certain reaction of the organism related to the oxidative stress. The study was made in the period May - August 2014, on a group of 16 Romanian Simmental dairy cows, kept on pasture during the day. The processing of the determined data were made using wavelet transforms (In-Place Fast Haar Wavelets Transform). The results of the experiment shown that when Temperature Humidity Indexes (THI) are higher than 72 (the superior limit for thermal comfort in cattle), the oxidative stress appeared in dairy cows. This oxidative stress was mainly manifested by the increasing of superoxide dismutase with 95\% in August compared to May, followed by the increasing of the catalase with 79\% and of glutathione peroxidase with 13\%. The increasing of the antioxidant enzymes levels was directly co-related with THI. We considered that the determination of the antioxidant enzymes level was an appropriate model for studying the influence of hot environment on the oxidative status of dairy cows. The wavelets transforms can be easier applied to practical data compared to the classical statistical methods.
\end{abstract}

Keywords: antioxidant enzymes, dairy cows, solar radiation, wavelets transforms

\section{INTRODUCTION}

This paper presents some of the results belonging to a larger study which wants to find out if the dairy cows are submitted to the heat stress induced by the solar radiation. On this purpose we previously determined different indexes, such as the main physiological indexes, haematological indexes, the level of the thyroid hormones and, in the end, the level of the antioxidants enzymes. The preliminary studies demonstrated that the month May represents the month for thermal comfort in cattle, which was considered the reference month and August was the month when the cows were submitted to the most increased thermal stress.

The purpose of this paper is to observe if in dairy cattle, exposed to solar radiation, could be noticed a certain reaction of the organism related to the oxidative stress, manifested by the increasing of the level of the antioxidant enzymes such as: superoxide dismutase (SOD), catalase and peroxidase in August comparing to May.

The organism is protected against oxidative stress by a series of enzymatic and non-enzymatic antioxidants, which interact together. These antioxidants systems have the role to control the forming and accumulation in the organism of the reactive oxygen species (ROS) may be formed in organism, both endogenous and exogenous under the action of some physico-chemical agents, such as: radiation, environmental pollution and the food intake with oxidative modified lipids (Dejica, 2000). The solar radiation acts, also directly and also indirectly by increasing the values of environmental temperatures. The most common 
index of heat stress: Temperature - Humidity Index (THI) is calculated from the temperature and relative humidity (Yousef, 1967). Dairy cows begin to suffer whenever the THI exceeds 72 (Jones, 1999: West, 2000).

Under these circumstances, it was recorded the formation, respective the accumulation in excess of the ROS which determines, so called "oxidative stress". This oxidative stress is defined as the totality of the oxidative degradations produced by the free oxygen radicals. (Olinescu, 1982). The oxidative stress is produced by the increasing of the free radicals or ORS production and / or by the reduction of the antioxidants defence, this determining the destruction of the macromolecules followed by metabolic disorders. (Bernabucci, 2002). When the formation of the ORS rate increases so that they can't be further neutralised by the action of the antioxidants systems, the oxidative stress is produced (Bernabucci, 2015).

The obtained individual data were processed using the wavelets transforms, which enables us to calculate the wavelet coefficients in order to make interpretation of the obtained results. The wavelets transforms are considered now a very modern method to be implemented in biology and this study represents one of the first attempt into this field. The fields of wavelets' applications enlarge because of their attractive properties for various purposes. The possibility to construct new wavelets with simplicity is one of the characteristics. Broadly defined, a wavelet is simply a wavy function carefully constructed to have certain mathematical properties. An entire set of wavelets is constructed from a single "mother wavelet" function, and this set provides useful "'building block" functions, each suitable for a different class of problems (Nievergelt, 1999, Ogden, 1999).

\section{MATERIAL AND METHODS}

The study was made on a group consisting in 16 Romanian Simmental milking cows, clinically health, kept on pasture during the day and in stable during the night. On the purpose to establish the level of the antioxidant enzymes, blood samples were taken on heparin, during days of May and August 2014. The blood samples were taken at 20,00 hours, each time after the cows were submitted to the solar radiation. The data obtained in May, considered as control data, were compared with those obtained in August.

During the days of the experiment there were also recorded the meteorological data, such as: air temperature, relative humidity and there were calculated the maximum THI index values. The meteorological data registration was made in Meteorological Station belonging to University of Agricultural Sciences and Veterinary Medicine Cluj-Napoca.

The determinations of the antioxidant enzyme's level were made in the Biochemistry Laboratory of the Faculty of Veterinary Medicine Cluj-Napoca.

The determination of SOD was made using NBT method, based on pyrogallic oxidation in the presence of nitro blue tetrazolium chloride (NBT) resulting a stained product which can be photometric dosed at $540 \mathrm{~nm}$ (Ciurdaru, 1999).

The catalase activity was made using photometric method with $\mathrm{K}_{2} \mathrm{Cr}_{2} \mathrm{O}_{7}$ (after Sinha, 1972, adapted by Andrei, 2004) which is based on the reaction of the hydrogen peroxide with potassium bichromate, in the presence of acetic acid, which forms a blue precipitate of perchromic acid. This precipitate is decomposed by heat, resulting a green coloured solution which can be estimated by a photometric reading at $\lambda \max =570$ nm.

The determination of peroxidase activity was made using the guaiacol method, which is based on the guaiacol oxydation as hydrogen donor, in the decomposition of the hydrogen peroxide by the peroxidase, resulting a coloured product which can be photometrically dosed at $470 \mathrm{~nm}$ (Ciurdaru, 1999).

The obtained mean values of the SOD, catalase and peroxidase activity were processed using wavelet transforms. A wavelet transform (WT) decomposes a signal (i.e. a sequence of numerical measurements) into several groups (vectors) contain information about characteristics of the sequence at different scales. Coefficients at coarse scales capture gross and global features while coefficients at fine scales contain local details. Further, it was explained the practical significance of wavelets coefficients considering the In-Place Fast Haar Wavelets Transform applied on real data.

The resulted data were also processed using ANOVA model implemented in R-Statistics. 


\section{RESULTS AND DISCUSSION}

In May, the calculated values for maximum THI were lower than 72 , varying between 43.4 and 67.5 , so they are within the limit for the thermal comfort in cows. On the contrary, the maximum THI index obtained in August was 78.4, being increased with $8.9 \%$ over the limit of 72 , which represents the limit over which the thermal discomfort appears in milking cows.

It has to be mentioned that the experimentally days, both in May and August, were chosen after five days of complete solar radiation, without any cloud or rain.

Our previous results showing an increase of the main physiological indexes (such as respiratory rate, heart rate, internal and cutaneous temperature, variation of the blood indexes and thyroid hormones) determined us to study the reaction of the cows' organism at the cell level, regarding the thermal stress. The obtained values of the antioxidant enzyme's levels are presented in Table 1.

The antioxidant enzymes levels were analysed by using In-Place Fast Haar Wavelet Transform which has been implemented in VBA in Microsoft Excel. In Figure1, Figure 2 respectively Figure 3, the sequence $s(5-0)$ contains the initial data and the sequence $s(5-5)$ displays the result (wavelet coefficients). In each case the transform generate $32=2^{5}$ coefficients, out of which it is to be taken into consideration the coefficient no.16, which present the variation of the values from May to August. The resulted values for the coefficients are presented in Table 2.

These coefficients show a general increase of the antioxidant enzyme levels, each value must be multiply with $(-2)$ in order to present the increasing of each type of antioxidant enzyme. So, the average increase of the enzymatic values in August compared to May is 29.16 for SOD (an increase of $95 \%$ in August compared to the May average), 1516.64 for catalase (an increase of 79\% in August compared to the May average) and 9.24 for glutathione peroxidase (an increase of 13\% in August compared to the May average).

The wavelets method exposed above appear to be a natural way to achieve vast improvements in the quality and in the quickness of statistical analysis of biological structures.

Also, we used ANOVA model, implemented in $\mathrm{R}$ Statistics, in order to investigate the effect of solar radiation on enzymes level. For ANOVA model, we consider the assumptions: normal distribution of errors within the respective groups, homogeneity of variances and independent data. We tested the homogeneity of variances using Levene test. In order to accept the homogeneity of variances assumption, we transformed the data at a logarithmic scale.

The analysis of variance table of the considered model, for a confidence level of 0.95 provide the $\mathrm{p}$-value from Table 3. In each case, the $\mathrm{p}$-value shows a significant increase of enzymes level from May to August.

Normally, the organism is protected by a large series of antioxidant systems which interacts (Apel, 2004). These antioxidant systems have the control role in the process of forming and accumulation of the reactive oxygen species (ROS). In the animal organisms, the forming of the ROS is endogenous, at the level of mithocondrias, peroxisomes and lisosomes (Jezek, 2005; Jackson, 2009, Turrens, 1997, 2003).

Tab. 1. Values of the antioxidant enzymes level (mean \pm S.E.) in August compared to May

\begin{tabular}{ccccccc}
\hline & \multicolumn{2}{c}{$\begin{array}{c}\text { SOD Activity } \\
(\mathrm{U} / \mathrm{ml})\end{array}$} & \multicolumn{2}{c}{ Catalase Activity } & \multicolumn{2}{c}{ Glutathione Peroxidase } \\
& \multicolumn{2}{c}{ (Ncat/ml) } & \multicolumn{2}{c}{ Activity $(\mathrm{Px} / \mathrm{ml})$} \\
\cline { 2 - 7 } & May & August & May & August & May & August \\
\hline Mean & $30.57 \pm$ & $59.73 \pm$ & $1917.53 \pm$ & $3434.18 \pm$ & $70.58 \pm$ & $78.88 \pm$ \\
$(\mathrm{X} \pm \mathrm{SX})$ & 1.82 & 5.17 & 352.96 & 482.63 & 3.90 & 1.98 \\
\hline
\end{tabular}

Tab. 2. The values of the resulted wavelets coefficients

\begin{tabular}{ccc}
\hline SOD & Catalase & Peroxidase \\
\hline-14.58 & -758.32 & -4.61 \\
\hline
\end{tabular}


ROS are represented by the singlet oxygen, superoxide radical anion, hydrogen peroxide and their radicals. All ROS are strong oxidants, which determine the irreversible oxidative transformations of the cellular biomolecules. (Kierkman, 2007) These transformations were named peroxidation because they are initiated in the presence of the molecular oxygen. In the organism these ROS produce, so-called, lipoperoxidation, protein oxidation and the oxidation of the nucleic acids (Murphy, 2011).

At the cellular level the generation and accumulation of the ORS are controlled by antioxidant enzymatic systems, which include superoxide dismutase (SOD), present as Mn-SOD in mitochondria; $\mathrm{Cu}$ and $\mathrm{Zn}-\mathrm{SOD}$ in cytoplasm and extracellular by EC-SOD (Iliukha, 2001). The catalase and peroxidase are: glutation-peroxidase (GPx), lactoperoxidase (LPx), mieloperoxidase (MPx), cytochrom-peroxidase (cCPx) and thioredoxin peroxidase (TPx) (Nodberg, 2001). These enzymes have different location in the cellular compartments. So that, the catalase is located in mitochondria and peroxisomes, where also act the glutathione-peroxidase. In the cytoplasm the glutathione-peroxidase is coupled with SOD. In this way the protection of the subcellular structures is provided and in the same time the formation of the hydroxyl radicals is avoided. (Noori, 2012).

SOD is considered the most important enzyme, characteristic for the aerobic life, regarding the oxidative biochemical processes, and it is present in all living cells. Due to the fact that after the dismutase reaction the hydrogen peroxide is formed, the activation of the SOD is coupled with the catalase activity, enzyme which has as substrate the hydrogen-peroxide itself (Vetrano, 2005). The combined action of both enzymes is very important for the living organisms to counteract the effects of hydrogen peroxide as ORS, on one hand and on the other hand to prevent the reaction between the superoxide anion and hydrogen-peroxide, reaction in which the most aggressive ORS may be formed, represented by hydroxyl radical. In the animal blood the SOD has the most significant antioxidant activity. The catalase is an enzyme which exists also in all aerobic cells, being located in mitochondria and peroxisomes.

The peroxidases are widespread antioxidant enzymes in the aerobic organisms with the main role to catalyse the decomposition reaction of

\begin{tabular}{|c|c|c|c|c|c|c|}
\hline$\Delta$ & A & B & C & D & $E$ & $\mathrm{~F}$ \\
\hline 1 & & & & & & \\
\hline 2 & $\mathbf{n}$ & 5 & & & & \\
\hline 3 & & & & & & \\
\hline 4 & $s(5-0)$ & $s(5-1)$ & $s(5-2)$ & $s(5-3)$ & $s(5-4)$ & $s(5-5)$ \\
\hline 5 & 38.820 & 34.25 & 36.3025 & 31.28 & 30.5775 & 45.1575 \\
\hline 6 & 29.680 & 4.57 & 4.57 & 4.57 & 4.57 & 4.57 \\
\hline 7 & 37.660 & 38.355 & -2.0525 & -2.0525 & -2.0525 & -2.0525 \\
\hline 8 & 39.050 & -0.695 & -0.695 & -0.695 & -0.695 & -0.695 \\
\hline 9 & 21.850 & 20.66 & 26.2575 & 5.0225 & 5.0225 & 5.0225 \\
\hline 10 & 19.470 & 1.19 & 1.19 & 1.19 & 1.19 & 1.19 \\
\hline 11 & 40.250 & 31.855 & -5.5975 & -5.5975 & -5.5975 & -5.5975 \\
\hline 12 & 23.460 & 8.395 & 8.395 & 8.395 & 8.395 & 8.395 \\
\hline 13 & 25.850 & 33.245 & 31.3925 & 29.875 & 0.7025 & 0.7025 \\
\hline 14 & 40.640 & -7.395 & -7.395 & -7.395 & -7.395 & -7.395 \\
\hline 15 & 32.260 & 29.54 & 1.8525 & 1.8525 & 1.8525 & 1.8525 \\
\hline 16 & 26.820 & 2.72 & 2.72 & 2.72 & 2.72 & 2.72 \\
\hline 17 & 28.450 & 32.14 & 28.3575 & 1.5175 & 1.5175 & 1.5175 \\
\hline 18 & 35.830 & -3.69 & -3.69 & -3.69 & -3.69 & -3.69 \\
\hline 19 & 27.530 & 24.575 & 3.7825 & 3.7825 & 3.7825 & 3.7825 \\
\hline 20 & 21.620 & 2.955 & 2.955 & 2.955 & 2.955 & 2.955 \\
\hline 21 & 86.280 & 60.26 & 52.745 & 47.425 & 59.7375 & -14.58 \\
\hline 22 & 34.240 & 26.02 & 26.02 & 26.02 & 26.02 & 26.02 \\
\hline 23 & 50.640 & 45.23 & 7.515 & 7.515 & 7.515 & 7.515 \\
\hline 24 & 39.820 & 5.41 & 5.41 & 5.41 & 5.41 & 5.41 \\
\hline 25 & 38.930 & 41.39 & 42.105 & 5.32 & 5.32 & 5.32 \\
\hline 26 & 43.850 & -2.46 & -2.46 & -2.46 & -2.46 & -2.46 \\
\hline 27 & 46.320 & 42.82 & -0.715 & -0.715 & -0.715 & -0.715 \\
\hline 28 & 39.320 & 3.5 & 3.5 & 3.5 & 3.5 & 3.5 \\
\hline 29 & 41.260 & 44.82 & 63.55 & 72.05 & -12.3125 & -12.3125 \\
\hline 30 & 48.380 & -3.56 & -3.56 & -3.56 & -3.56 & -3.56 \\
\hline 31 & 85.540 & 82.28 & -18.73 & -18.73 & -18.73 & -18.73 \\
\hline 32 & 79.020 & 3.26 & 3.26 & 3.26 & 3.26 & 3.26 \\
\hline 33 & 80.470 & 81.615 & 80.55 & -8.5 & -8.5 & -8.5 \\
\hline 34 & 82.760 & -1.145 & -1.145 & -1.145 & -1.145 & -1.145 \\
\hline 35 & 85.250 & 79.485 & 1.065 & 1.065 & 1.065 & 1.065 \\
\hline 36 & 73.720 & 5.765 & 5.765 & 5.765 & 5.765 & 5.765 \\
\hline
\end{tabular}

Fig. 1. SOD's Transform worksheet

\begin{tabular}{|c|c|c|c|c|c|c|}
\hline 4 & A & B & C & D & $E$ & $\mathrm{~F}$ \\
\hline \multicolumn{7}{|l|}{1} \\
\hline 2 & n & 5 & & & & \\
\hline 3 & & & & & & \\
\hline 4 & $s(5-0)$ & $s(5-1)$ & $s(5-2)$ & $s(5-3)$ & $s(5-4)$ & $s(5-5)$ \\
\hline 5 & 492.000 & 480 & 788.5 & 1509.813 & 1917.531 & 2675.859 \\
\hline 6 & 468.000 & 12 & 12 & 12 & 12 & $\quad 12$ \\
\hline 7 & 692.500 & 1097 & -308.5 & -308.5 & -308.5 & -308.5 \\
\hline 8 & 1501.500 & -404.5 & -404.5 & -404.5 & -404.5 & -404.5 \\
\hline 9 & 1771.000 & 2152.5 & 2231.125 & -721.313 & -721.313 & -721.313 \\
\hline 10 & 2534.000 & -381.5 & -381.5 & -381.5 & -381.5 & -381.5 \\
\hline 11 & 412.500 & 2309.75 & -78.625 & -78.625 & -78.625 & -78.625 \\
\hline 12 & 4207.000 & -1897.25 & -1897.25 & -1897.25 & -1897.25 & -1897.25 \\
\hline 13 & 4821.000 & 4672 & 3131 & 2325.25 & -407.719 & -407.719 \\
\hline 14 & 4523.000 & 149 & 149 & 149 & 149 & 149 \\
\hline 15 & 1528.000 & 1590 & 1541 & 1541 & 1541 & 1541 \\
\hline 16 & 1652.000 & -62 & -62 & -62 & -62 & -62 \\
\hline 17 & 1423.000 & 1384 & 1519.5 & 805.75 & 805.75 & 805.75 \\
\hline 18 & 1345.000 & 39 & 39 & 39 & 39 & 39 \\
\hline 19 & 1526.000 & 1655 & -135.5 & -135.5 & -135.5 & -135.5 \\
\hline 20 & 1784.000 & -129 & -129 & -129 & -129 & -129 \\
\hline 21 & 2852.000 & 3687.5 & 2972 & 3904.063 & 3434.188 & -758.328 \\
\hline 22 & 4523.000 & -835.5 & -835.5 & -835.5 & -835.5 & -835.5 \\
\hline 23 & 2801.000 & 2256.5 & 715.5 & 715.5 & 715.5 & 715.5 \\
\hline 24 & 1712.000 & 544.5 & 544.5 & 544.5 & 544.5 & 544.5 \\
\hline 25 & 6024.000 & 6069 & 4836.125 & -932.063 & -932.063 & -932.063 \\
\hline 26 & 6114.000 & -45 & -45 & -45 & -45 & -45 \\
\hline 27 & 1201.500 & 3603.25 & 1232.875 & 1232.875 & 1232.875 & 1232.875 \\
\hline 28 & 6005.000 & -2401.75 & -2401.75 & -2401.75 & -2401.75 & -2401.75 \\
\hline 29 & 6326.500 & 5870.25 & 3834.875 & 2964.313 & 469.875 & 469.875 \\
\hline 30 & 5414.000 & 456.25 & 456.25 & 456.25 & 456.25 & 456.25 \\
\hline 31 & 1585.000 & 1799.5 & 2035.375 & 2035.375 & 2035.375 & 2035.375 \\
\hline 32 & 2014.000 & -214.5 & -214.5 & -214.5 & -214.5 & -214.5 \\
\hline 33 & 1657.500 & 1811.25 & 2093.75 & 870.5625 & 870.5625 & 870.5625 \\
\hline 34 & 1965.000 & -153.75 & -153.75 & -153.75 & -153.75 & -153.75 \\
\hline 35 & 2018.000 & 2376.25 & -282.5 & -282.5 & -282.5 & -282.5 \\
\hline 36 & 2734.500 & -358.25 & -358.25 & -358.25 & -358.25 & -358.25 \\
\hline
\end{tabular}

Fig. 2. Catalase' s Transform worksheet 
$\mathrm{H}_{2} \mathrm{O}_{2}$ in the presence of a hydrogen donor. A very important enzyme, belonging to the antioxidant enzymatic systems of the body is glutathione peroxidase (Se-GPx), which catalyses peroxides decomposition, including that of hydrogen peroxide. The active site of the enzyme contains selenium as selenium-cysteine. (Ursini et al., 1995). The activity of this enzyme is correlated with the catalase activity.

The oxidative stress is produced by the increasing rate of free radicals production or ORS and/or by the decreasing of the antioxidant defence determined by metabolic disturbances. (Travisan 2001, quot. by Bernabucci, 2002). So, when the ORS speed formation increases they can't be neutralized any longer by the antioxidant enzymes action and the oxidative stress is produced. (Sies, 1991, quot. by Bernabucci, 2002).

The increasing of the antioxidant enzymes level proofs that, during the hot summer day, when the values of the THI index are higher then 72 , which is the limit value for the thermal comfort, the cows were exposed to heat stress. We found that between the increasing of the blood level of the antioxidants enzymes and the THI values exist a direct correlated relation, so that means that when the values of THI exceed 72 , the production of the antioxidant enzymes at the blood level starts to increase. The increasing of the antioxidants enzymes is due to the fact that in the animals organism the ORS are accumulated and the organism, by increasing the level of the antioxidant enzymes is trying to "neutralise" them. This can be explained by the hyperventilation which determines hyperoxia at the cell level and which is produced in the conditions of heat stress in cows. Under the hyperoxia conditions, the level of lipids and protein oxidation is increased, which determines the producing of ORS and as a

\begin{tabular}{|c|c|c|c|c|c|c|}
\hline$\Delta$ & A & B & C & D & $\mathrm{E}$ & $\mathrm{F}$ \\
\hline \multicolumn{7}{|l|}{1} \\
\hline 2 & $\mathbf{n}$ & 5 & & & & \\
\hline 3 & & & & & & \\
\hline 4 & $s(5-0)$ & $s(5-1)$ & $s(5-2)$ & $s(5-3)$ & $s(5-4)$ & $s(5-5)$ \\
\hline 5 & 79.950 & 72.61 & 74.735 & 70.3075 & 71.27625 & 75.89406 \\
\hline 6 & 65.270 & 7.34 & 7.34 & 7.34 & 7.34 & 7.34 \\
\hline 7 & 75.520 & 76.86 & -2.125 & -2.125 & -2.125 & -2.125 \\
\hline 8 & 78.200 & -1.34 & -1.34 & -1.34 & -1.34 & -1.34 \\
\hline 9 & 49.630 & 63.155 & 65.88 & 4.4275 & 4.4275 & 4.4275 \\
\hline 10 & 76.680 & -13.525 & -13.525 & -13.525 & -13.525 & -13.525 \\
\hline 11 & 78.650 & 68.605 & -2.725 & -2.725 & -2.725 & -2.725 \\
\hline 12 & 58.560 & 10.045 & 10.045 & 10.045 & 10.045 & 10.045 \\
\hline 13 & 77.810 & 53.58 & 65.48 & 72.245 & -0.96875 & -0.96875 \\
\hline 14 & 29.350 & 24.23 & 24.23 & 24.23 & 24.23 & 24.23 \\
\hline 15 & 79.420 & 77.38 & -11.9 & -11.9 & -11.9 & -11.9 \\
\hline 16 & 75.340 & 2.04 & 2.04 & 2.04 & 2.04 & 2.04 \\
\hline 17 & 76.890 & 68.28 & 79.01 & -6.765 & -6.765 & -6.765 \\
\hline 18 & 59.670 & 8.61 & 8.61 & 8.61 & 8.61 & 8.61 \\
\hline 19 & 85.280 & 89.74 & -10.73 & -10.73 & -10.73 & -10.73 \\
\hline 20 & 94.200 & -4.46 & -4.46 & -4.46 & -4.46 & -4.46 \\
\hline 21 & 86.740 & 83.38 & 85.24 & 81.49375 & 80.51188 & -4.61781 \\
\hline 22 & 80.020 & 3.36 & 3.36 & 3.36 & 3.36 & 3.36 \\
\hline 23 & 90.240 & 87.1 & -1.86 & -1.86 & -1.86 & -1.86 \\
\hline 24 & 83.960 & 3.14 & 3.14 & 3.14 & 3.14 & 3.14 \\
\hline 25 & 76.620 & 79.22 & 77.7475 & 3.74625 & 3.74625 & 3.74625 \\
\hline 26 & 81.820 & -2.6 & -2.6 & -2.6 & -2.6 & -2.6 \\
\hline 27 & 72.930 & 76.275 & 1.4725 & 1.4725 & 1.4725 & 1.4725 \\
\hline 28 & 79.620 & -3.345 & -3.345 & -3.345 & -3.345 & -3.345 \\
\hline 29 & 84.200 & 73.19 & 73.395 & 79.53 & 0.981875 & 0.981875 \\
\hline 30 & 62.180 & 11.01 & 11.01 & 11.01 & 11.01 & 11.01 \\
\hline 31 & 70.280 & 73.6 & -0.205 & -0.205 & -0.205 & -0.205 \\
\hline 32 & 76.920 & -3.32 & -3.32 & -3.32 & -3.32 & -3.32 \\
\hline 33 & 78.630 & 79.535 & 85.665 & -6.135 & -6.135 & -6.135 \\
\hline 34 & 80.440 & -0.905 & -0.905 & -0.905 & -0.905 & -0.905 \\
\hline 35 & 90.350 & 91.795 & -6.13 & -6.13 & -6.13 & -6.13 \\
\hline 36 & 93.240 & -1.445 & -1.445 & -1.445 & -1.445 & -1.445 \\
\hline
\end{tabular}

Fig. 3. Peroxidase's Transform worksheet

Tab. 3. The $p$ values of antioxidant enzymes

\begin{tabular}{ccc}
\hline SOD Activity & Catalase Activity & $\begin{array}{c}\text { Glutation Peroxidase } \\
\text { Activity }\end{array}$ \\
\hline $\mathrm{p}$-value $=0.001<0.05$ & $\mathrm{p}$-value $=0.017<0.05$ & $\mathrm{p}$-value $=0.044<0.05$ \\
\hline
\end{tabular}


consequence the level of the antioxidants enzymes increases.

The action of the environmental factors on different physiological traits were also recorded by other authors. Nagy et al., (2004) found influences of environmental factors on weaning performances on Hungarian grey cattle population. Pavani et al. (2015) studied the reproductive performances of Holstein dairy cattle in dry-summer subtropical climatic conditions. Nikahh et al., (2016), studied the seasonal and group effects on dairy cow behavior in large yards. Qi L et al., (2015) made different studies regarding climatic effects and productivity in Wisconsin dairy farms. Komisarek et al. (2016) found differences on milk production traits in dairy cows depending on environmental temperature.

\section{CONCLUSIONS}

During the hot summer days, when the values of THI exceed 72, the oxidative stress is produced in dairy cows, which is mainly manifested by the increasing of the antioxidant enzymes activity.

The oxidative stress in milking cows is mainly manifested by the increasing of the SOD with 95\% in August comparing to May, followed by the increasing of the catalase level with $79 \%$ and of the general peroxidase with $13 \%$.

The SOD is the most significant enzyme belonging to the antioxidant system that increases its level in dairy cows exposed to heat stress induced by solar radiation.

There was recorded a direct correlation between the increasing of the antioxidant enzymes level and the increasing of the THI.

The increasing of the activities of the enzymes of the antioxidant system in blood seems to represent an adaptative response of dairy cows exposed to caloric stress. The wavelets transform can be easily adapted to biological data, due to the fact that the coefficients are easy to be calculated, and the interpretation of the data may easier and faster be made compared to the classical statistical methods.

\section{REFERENCES}

1. Andrei S, Bunea A, Pintea A (2014). Stresul oxidativ şi antioxidanţi naturali. Cluj-Napoca, Romania, Editura Academic Pres.
2. Apel K, Hirt H (2004). Reactive oxygen species: Metabolism, oxidative stress and signal transduction. Annu Rev Plant Biol 55:373-399.

3. Bernabucci U, Ronchi B, Lacetera N, Nardone A (2002). Markers of Oxidative Status in Plasma and Erythrocytes of Transition Dairy Cows During Hot Season. J Dairy Sci 85: 2173- 2179.

4. Bernabucci U, Basirico L, Morera P, Dipasquale D, Cappelli FP, Calamari L (2015). Effect of summer season on milk protein fractions in Holstein cows. J Dairy Sci 98(3): 18151827.

5. Ciurdaru V, Andrei S, Pintea A, Bele C (2001). Biochimie medicală veterinară - metode şi tehnici de laborator. ClujNapoca, Romania: Editura AcademicPres.

6. Dejica D (2000). Stresul oxidativ în bolile interne. ClujNapoca, Romania: Editura Casa Cărţii de Ştiință.

7. Ilyukha VA (2001). Superoxide dismutase and catalase in the organs of mammals of different ecogenesis. Journal of Evolutionary Biochemistry and Physiology 37(3):241245.

8. Jackson M, Pye D, Palomero J (2009). The production of reactive oxygen and nitrogen species by skeletal muscle. J Appl Physiology 102:1664-1670.

9. Jezek P, Hhlavata L (2005). Mitochondria in homeostasis of reactive oxygen species in cell, tissues and organism. The International Journal of Biochemistry\&Cell Biology 37:2478-2503.

10. Jones GM, Stallings CC (1999). Reducing Heat Stress for Dairy Cattle. Virginia Cooperative Extension. Dairy Publication 404-200.

11. Kierkman HN, Gaetani GF (2007). Mammalian catalase: a venerable enzyme with new mysteries. Trends in Biochemical Sciences 32(1):44-50.

12. Komisarek J, Kolenda M (2016). The effect of DGAT1 polymorphism on milk production traits in dairy cows depending on environmental temperature. Turk J Vet Anim. Sci. 40: 251-254.

13. Murphy MP, Holmgren A, Larsson NG, Halliwell B, Chang CJ (2011).Unravelingthe biological roles of reactive oxygen species. Cell Metab 13:361-366.

14. Nagy B, Lengyel Z, Bodo I, Gera I, Torok M, Szabo F (2004). Effect of some environmental factors on weaning performance of Hungarian grey cattle populations. Journal of Central European Agriculture 5(3): 143-150.

15. Nievergelt Y (1999). Wavelets Made Easy. Boston. Birkhauser.

16. Nikkhah A, Kowsar R (2012). Seasonal and group effects on dairy cow behavior in large yards. Turk J Vet Anim Sci 36(2): 123-129.

17. Nodberg J, Arner E (2011). Reactive oxygen species, antioxidants and mammalian thioredoxin system. Free radical Biology \& Medicine 31(11):1287-1312.

18. Noori S (2012). An overview of oxidative stress and antioxidant defensive system, 1:413.doi:10.4172/ scientificreports 413 .

19. Ogden TR (1999). Essential Wavelets for Statistical Applications and Data Analysis. Boston. Birkhauser. 
20. Olinescu R (1982). Peroxidarea în chimie, biologie şi medicină. Bucureşti, Romania: Editura Ştiinţifică şi Enciclopedică.

21. Pavani K, Carvalhais I, Faheem M, Chaveiro A, Reis FV, da Silva FM (2015). Reproductive Performance of Holstein Dairy Cows Grazing in Dry-summer Subtropical Climatic Conditions: Effect of Heat Stress and Heat Shock on Meiotic Competence and In vitro Fertilization. AsianAustral Asian Journal of Animal Sciences 28(3): 334-342.

22. Qi L, Bravo-Ureta BE, Cabrera VE (2015). From cold to hot: Climatic effects and productivity in Wisconsin dairy farm. J Dairy Sci 98 (12): 8664-8677.

23. Turrens J (1997). Superoxide production by the mitochondrial respiratory chain. Bioscience Reports 17 (1).

24. Turrens J (2003). Mitochondrial formation of reactive oxygen species. J Physiol 552(2):335-344.
25. Ursini F, Maiorino M, Aumann K, Roveri A (1995). The diversity of glutation peroxidase, Methods in epidemiology 252: 38-53.

26. Vetrano AM, Heck DE, Mariano TM, Mishin V, Laskin JD (2005). Characterization of the oxidase activity in mammalian catalase. The Journal of Biological Chemistry 280:35372-35381.

27. West JW (2000). Management Considerations for the Dairy Cow during Heat Stress. University of Georgia, Costal Plain Experiment Station, Tifton Campus.

28. West JW (2003). Effects of Heat-Stress on Production in Dairy Cattle. Journal of Dairy Science 86(6): 2131- 2144.

29. Yousef MK, Johnson HD (1967). Physiological Thermoneutrality Zones of Cattle. Biometeorology 2: 477484. 